\title{
THE ANALYST.
}

A UGUST, 1888 .

\author{
PROCEEDINGS OF THE SOCIETY OF PUBLIC ANALYSTS. \\ POLLUTED DRINKING WATER AND THE CLOSURE OF WELLS. \\ BY ALFRED HILL, M.D., F.I.C. \\ (Read at the Meeting, June 20, 1888.)
}

Professional and even public opinion has long been opposed to the use, for drinking, of water polluted by excrementitious matters or sewage ; the use of such water not only is repugnant to sentiment, but experience has proved that it sometimes produces serious disease and death. This fact has been recognised from the earliest historic times, and in the more enlightened and more scientific modern times it is still more frequently brought home to us. For the last half-century the subject has received greater attention than ever before, till it has come to be generally acknowledged that sewage-polluted water cannot be drunk with safety. This widespread impression has led, in many large communities, to the obtaining of Parliamentary powers to supply pure water from a distance, either from the surface of the earth in districts free from population, as Glasgow from Loch Katrine, Manchester from Thirlmere, and Liverpool from the source of the Severn, as Rome did from the distant Arno; or from the strata of the earth at points so deep as to be beyond the influence of surface filth, and to the abolition of the surface wells of such towns at one sweep.

These special and local Acts, as well as the Public Health Act, have served not only to confirm priblic opinion in favour of pure water, but they have also equally led the public to believe that it was only necessary to prove, either by common observation or by chemical means, the pollution of a water supply with animal matter, in order-in cases of wells especially - to enable the closure of such supplies to be effected. In some towns there has, however, been no general closure, but each well is chemically examined in detail, and closed if the circumstances warrant this proceeding. On the mere proof of such pollution hundreds of thousands of wells in the country have been closed : in some cases-notably with the Broad Street pump at Westminster-after injury being proved, but in most cases without any such proof whatever.

Two cases recently decided, however, have excited much surprise and disappointment, inasmuch as orders to close the polluted wells were refused, on the ground that it had not been proved that the waters were "injurious to health"; these words are from the 70th Section of the Public Health Act, 1875. One of these cases occurred at 
Enfield ; the other at Birmingham. The Enfield case was brought before the Society of Medical Officers of Health on the 18th of May by the analyst, Mr. Lloyd, who raised the question, What, in the words of the 70th Section of the Public Health Act, constituted "water injurious to health?" He said the presence of sewage matters in potable water, even when in large quantity, appeared not necessarily to do so, though if the sewage contained the germs of disease it would; and he mentioned eminent authorities who had shown "that no sufficient chemical variation, to be of a decisive character, existed," to indicate when pollution is injurious and when not. Bacteriology, he said, was equally at fault in proving the existence of disease germs. Recognising these facts, he had, he said, when reporting upon contaminated water, simply stated the water contained sewage, and was therefore unfit for drinking purposes, and this had sufficed in most cases to ensure the closing of the wells; but recently a contested case at Enfield was lost on the ground that the report did not use the words of the Act. The water in question contained :-Total solids, 83.72 ; loss on heat, $7 \cdot 0$. Oxygen absorbed, $0 \cdot 157$; $\mathrm{Cl}, 8.40 ; \mathrm{N}$, as nitrates, $2.28 ; \mathrm{NH}_{3} \cdot 084 ; \mathrm{Alb}^{\mathrm{d}} . \mathrm{NH}_{3} \cdot 008$. No water analyst of experience could, it would be supposed, do otherwise than condemn such a water, yet, singularly enough, two other chemists, whose analytical results agreed with Mr. Lloyd's, and who made their analyses independently, gave favourable reports of the water.

"The owner of the well disputed his report, and an analysis on his behalf was made by Mr. Gregory, who found practically the same result, with the exception of the nitrates, which he gives at $4 \cdot 22$, and who reported 'a perfectly safe water to use for drinking and domestic purposes, being free from any trace of sewage contamination.' In view of the conflicting evidence, the magistrate decided to send a sample to Dr. Bell at Somerset House, and he, in his report, stated that his results did not differ materially from the previous analyses. It was evident, he thought, from the large quantity of saline matters present, that it passed through a stratum of earth largely charged with sewage or organic refuse, and carried down with it various products resulting from the oxidation of the organic matter, which, though not dangerous to health, was very objectionable. As to how such a sentence came in the Act, he thought it was taken for granted that the mere presence of sewage in potable water was prima facie evidence that the water was injurious, and that view was supported by the fact that in the Sixth Report of the Rivers Commission on Domestic Water Supply river water receiving sewage, and shallow well waters were designated dangerous, without any consideration of the quantity of pollution. So long as Somerset House was made the court of appeal, it practically amounted to an inability to close polluted wells."

I have stated this case at some length because it is almost on a perfect parallel with the Birmingham case, in which the water was very similar, being better in some respects, but worse in others. The analytical results obtained by myself in 100,000 parts were as follows :-Total solids $148.2 ; \mathrm{NH}_{3} \cdot 001 ; \mathrm{Alb}^{\mathrm{d}}$. $\mathrm{NH}_{3} \cdot 015 ; \mathrm{N}$ as nitrates 6.6 ; chlorine $11 \cdot 2$.

As in the Enfield water, however, the point on which the whole case turned was the word "injurious." In my evidence I said the water presented all-round evidence of pollution with matter derived from sewage; it was therefore dangerous for domestic use. The counsel for the defence asked me this question: "Seeing before you the defendant, who is now in perfect health, and who has drunk the water daily for twenty-five years without any illness, do you mean to swear that, if he were to drink now a pint, or a quart of the water, or more, it would prove injurious to his health ?" I replied, "No ; it might not at the present time, though it might ; or, if not now, at some future time." The magistrate then asked me, "Do you say this well is injurious to health?" to which I replied, "No; I say it is dangerous, and likely to injure health at any moment." The 
magistrate then said, "I think we must dismiss the case." Mr. Parker, the Inspector of Nuisances: "On what ground, your worship?" Mr. Goodman: "You have not proved that the well is so polluted as to be injurious to health." It was true I had not, because I could not point to illness or death which had been produced by it, and I know of no other proof ; but I had proved all that chemical analysis enabled me to do-viz., that it was polluted in the same manner (that is, by animal matter) as many wells are which have been known to produce illness and death. Surely it was never intended by the Act that polluted wells are not to be closed until disease or death have resulted from their use ; and yet, as I had proved everything short of this, I don't know what other proof was left to be produced.

The failure of the Enfield and Birmingham prosecutions is not only disappointing, but very embarrassing in its influence on future action. I don't know how Mr. Lloyd has fared with his Authority, but in my case all the blame is put upon my shoulders, because I did not swear that the water was "injurious," and so comply with the wording of the Act. But how, as a conscientious witness, could I do this when I know, as we all know, that water contaminated by normal or uninfected sewage is drunk every day by millions of people with apparent impunity? My answer to the categorical question put to me by counsel as to whether a draught of the Birmingham well water in question would now injure the defendant would at once have neutralised any opinion of mine to the contrary in the minds of the Bench, and so the sacrifice of my convictions would have done no good, while it would have left me discredited in the opinion of conscientious men competent to judge of the question, and an object of life-long contempt to myself. A scientific witness is not an advocate; he should not be a partisan. It is his bounden duty to tell the truth, as far as he believes he knows it, "without fear, favour, or affection," and regardless of all consequences; he is not responsible for them; and then in any case, to whatever extent he may unjustly be made to suffer in " mind, body, or estate," he cannot be brought by any power to a lower condition than that of the defeated general, who, in retreating, cried, "All is lost but honour."

Less with the object of obtaining confirmation of my views than to educate and satisfy the doubts of others, I wrote to several acknowledged eminent water analysts and medical officers of health, asking their opinions on the words "injurious" and "dangerous." The following are some of their replies, the first three being from gentlemen having occupied and occupying the most important chemical and medico-chemical positions under Government-viz., Dr. Frankland, of the Rivers Pollution Commission; Dr. Dupré, Analyst to the Local Government Board; and Dr. Thomas Stevenson, Official Analyst to the Home Office:-

My deAr Dr. Hill,

"The Yews," Reigate, May $26 t h, 1888$.

In reply to your letter of the 19th inst., I am decidedly of opinion that no analytical results can justify the opinion that a particular sample of water is injurious to health, unless actual poisons are detected; but if the sample contains palpable evidence of pollution by animal organic matter, it is undoubtedly dangerous to health, inasmuch as it might be actually injurious at the time the sample was taken, or may become so at any moment.

With regard to the personal execution of analyses, it is neither possible nor desirable that the principal of a laboratory should personally make the analytical determinations; but they should be made under his direction or supervision, and the evidence of the assistant who actually makes them should be tendered if the results are challenged. I have often known this done, but I do not remember a case in which the assistant was actually called.

Believe me, yours very truly,

(Signed) E. FrankLand. 
[Copy.]

Laboratory, Westminster Hospital Medical School, Caxton Street, Westminster, S.W.,
Dear Dr. Hill,
June 15 th, 1888.

There cannot be the slightest doubt that the well water, details of the analysis of which you have furnished to me, is polluted to a very serious degree by sewage or similar matter-in fact, it is little else than sewage oxidized to a greater or lesser degree by filtration through soil. Such a water is totally unfit for use. At the same time, I quite agree with you that you could not conscientiously have sworn that the particular sample of water you analysed was injurious to health. All that a chemist can do in such a case, seeing that we have as yet no means of identifying any of the germs producing typhoid fever, cholera, etc., etc., is to state that the water is polluted by lanimal matter-probably excrementitious-and that it may at any time become injurious. What I usually do in such a case as this is to condemn the well, rather than the particular sample of water. If a water shows sewage pollution it may or may not be injurious; that depends upon circumstances at present beyond the ken of the water analyst, but at all events it proves that the well from which the sample of water has been taken must be in more or less direct communication with sewage matter, and, whenever such sewage matter contains the germs of disease, the water from the well will be dangerous to every one drinking it.

Yours very truly, (Signed) A. Dupré.

Dear Dr. HiLl,

Chemical Laboratory, Guy's Hospital, London, S.E.,

I have read with much interest your case of the refusal of the magistrates to order the closing of a well where you testified that the water was dangerous to health, although you very properly declined to say that the water was actually injurious to health; and $I$ have the figures of your analysis before me.

I think you were quite right in your opinion, and also in using the expression "dangerous." I am in the habit of using the term "dangerous" in my reports on such waters as this one you analysed, and of purpose. They are waters which expose the drinkers to risk, although individuals may again and again drink them without actual resulting harm. Without it can be shown that "injurious" and "dangerous" are synonymous terms, "dangerous" is the better and more correct expression.

Should the decision in your case be upheld, in future it will be well to use the word "injurious" with the qualification-i.e., "likely to injure health"-or to have the law altered. Believe me, yours very faithfully, (Signed) Tros. Stevenson.

From H. Tomkins, Esq., M.D., B.Sc., Medical Officer of Health, Leicester. Borough of Leicester, Health Department, Town Hall,

Dear Dr. HiLl,

Re "Polluted Water." 16 th June, 1888.

The analysis of the water (of which you sent me a copy) is sufficient to warrant its being condemned without hesitation, and I cannot understand your magistrates refusing to do so in the face of your evidence.

I have constantly condemned water less polluted than this, and have had no difficulty in getting wells closed on certifying that such is dangerous to health. Of course the absolute proof of its injury could only be sworn to after illness had been caused by it; but it appears to be a very anomalous position for any authority to be in, whose duty is to guard the public health against danger, to wait until injury has actually resulted.

I agree with you that, if justices take this view of the wording of the 70th Section, the sooner it is amended the better.

Yours faithfully, (Signed) Hy. Tomkins.

From Matthew A. Adams, Esq., F.R.C.S., Medical Officer of Health, County Analyst and Analyst for the Borough of Maidstone.

Dear Dr. Hill,

Ashford Road, Maidstone, 16 th June, 1888.

I am quite of your opinion as to the danger of allowing such a water as you send me particulars of to be used for drinking purposes. The great excess of solid matter (unless otherwise explained), the high chlorine, and particularly the great excess of nitrates, make it, in my opinion, imperative that the well should be closed because of the constant risk to those drinking it.

Of course it is impossible for anyone-chemist or other-without actual demonstration to say that any polluted water, for the time being, is positively "injurious," and it is unreasonable to 
suppose that the P.H. Act would require an analytical opinion on the subject, if the injurious properties of a water could be otherwise, legally and more directly, demonstrated. It would hardly do to administer the water in question to a susceptible person to test the opinion. The fact is, as all properly informed persons well know, an opinion in such cases can be based on inference alone.

Perhaps the enclosed "extract," which further explains my views and my mode of dealing with such cases, will interest you. Yours faithfully,

(Signed) Matthew A. Adams.

From Dr. Walter J. Sykes, late Medical Officer of Health and Public Analyst for Portsmouth.

\author{
The Laboratory, \\ 11, Billiter Square, \\ London, E.C., \\ June $18 t h, 1888$.
}

Dear Dr. Him,

I duly received yours enclosing analysis of a sample of water. There can be no two opinions on the matter; it is an exceedingly polluted water, and totally unfit for human consumption. I consider your qualification "dangerous" to be the correct one; it is a water receiving a large quantity of animal organic pollution, and, though at present the large amount of this is being oxidised into harmless nitrogen compounds, yet no one can foresee how soon this action may cease; and when it does, either temporarily or permanently, disease and probably death will be the result.

I have had to regret on many occasions that the bench adopt such literal interpretations of the wording of the Public Health Act. It has several times happened to me to be unable to get "dangerous" drainage arrangements altered, because I could not positively say they were "injurious" at the time. This is a great stumbling block in the way of preventive medicine, as, though we are able to point out dangers ahead, we cannot get them removed, but we must first wait until some serious illness or death has been the result. Believe me, yours faithfully,

(Signed) WhLTER J. Sykes, M.D., D.P.H.

From Dr. Alfred Ashby, Medical Officer of Health and Public Analyst for Reading Urban Sanitary Authority.

Dear Dr. Hill,

Town Hall, Reading, June 18 th, 1888.

There can be no doubt the water you allude to in your letter ought not to be allowed to be drunk; but, although $I$ have frequently got polluted wells closed on similar evidence to yours, I have long anticipated that such a line of defence as that you describe would be taken in some polluted water case, owing to the unfortunate wording of Section 70 Public Health Act, 1875.

Of course we all know that polluted water may be drunk for a long time without causing actual disease, in the same way that any unhealthy condition within the meaning of the 91st Section of the Public Health Act may exist for a long time without actually causing disease; but that the water is under the most favourable conditions for widely disseminating disease as soon as the infective material is added to its ordinarily contained filth.

If these sections are to be interpreted in their literal sense, and we have in all cases to prove that some actual person has been made ill before proceedings can be successful, the sooner we give up our work the better. Such an interpretation is certainly opposed to the spirit of the Act of 1875 , which is preventive; and, if we were always bound by it, the greater part of the improvement in the public health which has been effected during the past fifteen years would not have taken place.

The evidence you gave in the case you refer to was perfectly correct, for you could have given no other reply to the question put to you.

I am, yours very faithfully,

(Signed) Alfred Ashby.

I have been asked if I could not see my way to saying that I regarded the words "injurious" and "dangerous" as synonymous. Unfortunately this is impossible, because I have, like Dr. Frankland, Dr. Dupré, and others, already and always rigidly maintained the distinction. As long as the single hair is strong enough to support the sword over the head of Damocles, who sits beneath it, his life is only in danger ; if that hair should break he will be injured. The thoughtless person, smoking his pipe while sitting on a barrel of gunpowder, is only in danger as long as the spark and the powder are 
kept apart; but in the opposite case he will be certainly injured. Surely the distinction between danger and injury is plain enough, but is it wise to wait for the breaking of the hair or the explosion of the powder before taking steps to prevent injury? That the object of the Public Health Act is to prevent injury is undeniable, and I maintain, therefore, that the sanitarian having pointed out the danger, it is for the legal tribunal to read and interpret the Act in that sense-I mean as a preventive Act-and order the removal of the danger. In the Sanitary Record of last month is a report of two wells which were closed at Halifax. The analysts, Mr. Ackroyd, of Halifax, and Mr. Jarmain, of Huddersfield, reported in accordance with my view of the case. The former said that the waters were "contaminated and dangerous to drink"; the latter, that they were "polluted with sewage or drainage from manured land." I suppose that if there had been no evidence beyond this the case would have broken down, but I hear indirectly that Mr. Ainley, the Medical Officer of Health, in agreeing with the chemical reports, went further, and swore the waters were injurious to health, although there was no actual proof of it.

Probably if the Birmingham case had had the benefit of a legal representative to conduct it, such a view would have been put forward and supported by the context of. the section as would have influenced the court to regard the case differently; but there was little chance of my obtaining a different decision, altogether unsupported as I was hy legal or other aid, while opposed by two solicitors, two eminent and leading counsel, and, as I am informed, six chemists, headed, I know, by Dr. Attfield and Mr. Wanklyn. Such an array of legal and chemical machinery, with a bench not qualified by special training, either legal, medical, or chemical, to adjudicate on such a question, was, of course, entirely irresistible.

A refusal of a closing order was almost inevitable, but even in that case all was not necessarily lost, for our legal advocate, if we bad had one, could still have asked for a case on which to found an appeal, and I have little doubt that a higher court would have ruled otherwise.

Now, it appears to me that the question for this Society to consider is what is to be done under the circumstances, and I shall be very glad to hear the views and obtain the decision of my fellow-members upon it. It appears to me there are three ways of overcoming the difficulty, for of course we are all anxious to find a way out of it in the interests of public henlth.

The first, about which, however, I am not very sanguine, is to get magistrates to accept the secondary meaning of injurious-that is, "tending to injure," "calculated to injure." If this signification of the word were taken, we could all use it without hesitation, and so comply not only with the spirit, but with what is much more appreciated generally-with the absolute letter of the Act.

Secondly, a case properly conducted by a legal representative might be taken into court on the evidence that the water was "dangerous and unfit for use," and, on an urder for closure being refused, a case asked for, when, on appeal, the question would be argued to a satisfactory termination.

Thirdly, with or without such test case and appeal to a higher tribunal, the Governwucnt could be memorialised by Local Authorities, medical and chemical societies, and others to amend the 70 th Clause so far as to bring it into conformity with the practical common-sense and science of the day and the reasonable demands of sanitary progress.

Discussion.

The President said that the subject which Dr. Hill had brought before the Society was one of extreme importance to everyone. It seemed to him almost im- 
possible for anyone to afirm positively that a polluted water would necessarily be injurious to health, remembering that such active poisons as opium and arsenic were habitually taken by individuals without injury to health, and that habit enabled the doses to be enormously increased. It would not be possible to say of a water that actually contained arsenic, that it would be necessarily injurious to the health of drinkers, although certainly it would be dangerous to health. In Sheffield they had recently some hundreds of cases of poisoning by lead, but the instances in which people had suffered were only a fraction of those in which people had drunk the same water with impunity, from which it must be concluded that only those people who were unusually susceptible to the influence of lead were affected under the conditions which prevailed. Similarly with sewage-contaminated water, which might be drunk by many persons, and especially those habituated to it, with impunity, while others would be immediately rendered dangerously ill. Of course too, as had been remarked, much depended on whether the sewage was excreted by persons in health, or those suffering from disease. The only possible way of ascertaining that a particular water would be actually injurious would be to experiment on human beings who had been previously accustomed to drink water of unexceptionable origin. A single experiment of this sort even would not suffice, as personal idiosyncrasy might prevent the poison from acting. $\mathrm{He}$ mentioned this to show how impracticable it was to affirm positively that a water was injurious to health. In the case of water which had suffered contamination by sewage, and in which the polluting matter had subsequently undergone oxidation, as was the case with the sample in question, he was in the habit of certifying that a change of conditions might render the water positively dangerous.

It was a great misfortune that, owing to circumstances well known to the members of the Society, many medical officers of health, and some professional chemists, were in the habit of ignoring the evidence of previous pollution furnished by the presence of nitrates and nitrites, and this in the face of the River Pollution Commissioners' results, which showed that filtration of fresh sewage through five or six feet of gravelly soil caused the oxidation of all the ammonia to the so-called "harmless" nitrates and nitrites. But if the process of spontaneous purification by oxidation were interrupted, as by the pores of the soil becoming saturated with water through heavy rains, or other causes, the oxidation was liable to be incomplete, and the character of the water would suffer a corresponding change.

With regard to the particular case of Dr. Hill, it was lamentable to think that any professional chemist should have been ready to appear for the defence of such a case. He could not quite understand how it was that there was no lawyer to conduct the case. Did Dr. Hill suggest that he could not have had the service of a lawyer if he desired? It seemed to him that the case was just one of those where the recognised solicitor of the Society might have been advantageously retained.

Mr. LlOYD proposed that the Society should act in conjunction with the Society of Medical Officers of Health in bringing the question before the Local Government Board, with a view to getting the objectionable clause altered. He protested against the tendency of magistrates to regard Somerset House as a court of appeal, and deplored the effect that Dr. Hill's case would have on the future decisions of magistrates, who would take it as a precedent, making it difficult to close any well. It was well known that a polluted water might be drunk habitually with impunity by persons long accustomed to it-probably having become so by degrees as its impurity increased-while a stranger coming into the district might experience very serious effects. He called attention to the terms of Dr. Bell's report on the water-namely, that it appeared to have filtered through a stratum charged with sewage or other decomposing animal matter, whereby 
it was rendered objectionable, though not absolutely dangerous to health. Some outbreaks of diphtheria have occurred in Halifax which are probably to be ascribed to the use of water from shallow wells contaminated with sewage. $\mathrm{He}$ concluded by emphasizing the necessity of the case being taken up by the Society of Public Analysts.

Dr. Staton, speaking for the Council of the Society of Medical Officers of Health, agreed that the matter must be thoroughly looked into. At Nottingham and Birmingham many wells had been closed without trouble or dispute. Nuisances-e.g., those arising from the use of privy-middens-which are analogous to this, were satisfactorily dealt with at Nottingham, until the same point was raised, and with the same resulti.e., interruption of the work of alteration; but at Bradford the Corporation came to the opposite conclusion on the same question. It was necessary, therefore, that a definite legal decision should be obtained.

Prof. Brschof, though at first misunderstanding Dr. Hill's position with regard to the use of the word "dangerous" instead of "injurious," on grasping his meaning, fully endorsed his views. He would suggest that an attempt should be made on the next occasion to induce the magistrate to accept the phrase, "likely to be injurious to health," as complying with the requirements of the Act.

Mr. Adams related a similar case which had happened to himself. A well contained a large quantity of nitrates, and, as he could not swear that it was literally "injurious to health," the magistrates refused to close it. In consequence, the Local Government Board, who had instituted the case, announced it as their opinion that it should have been referred to a " more capable man," who would have been able to make a statement sufficiently positive to cause the magistrates to close the well.

Dr. Dupré said this was not the first case of the kind. Mr. Hehner and himself were engaged in a similar case some years ago in the Isle of Wight, when the magistrate, after hearing the case, said, "Now, sir, the case is dismissed, but if any one of your cus tomers is seized with cholera you will be held responsible," and yet the magistrate did not feel justified in closing the well. He should like also to mention that some years ago he made a great number of analyses for Dr. Buchanan of waters purposely polluted. To one of these Dr. Cory had added a minute quantity of typhoid stool, and neither Dr. Frankland nor himself discovered the pollution, and this is what Dr. Buchanan wrote, chiefly in consequence of that analysis and of the outbreak which happened at Caterham, where a man suffering from typhoid fever had misconducted himself while down a well under repair :- " The chemist can, in brief, tell us of impurity and hazard, but not of purity and safety. For information about these we must go, with the aid of what the chemist has been able to teach us, in search of the surrounding water sources and affecting water services."

Now it should be borne in mind that this was written, not in relation to a water obviously polluted, but mainly in regard to waters so slightly polluted that the chemist was unable to find it out. Dr. Buchanan is, therefore, strongly of opinion that whenever analysis shows sewage pollution the water might at any time become injurious to health. In his (the speaker's) reports, whenever he found evidence of sewage contamination he always emphasized the fact that the well being within the influence of sewage might at any time become injurious to health. So far as he knew there were no means at present in the hands of the chemist to enable him to say that a water was polluted by any definite disease germs, and, therefore, whenever he could prove sewage pollution he should condemn the well, not because the water was necessarily injurious at that time, but because, in certain events, i.e., the occurrence of an infectious disease among the people contributing to the pollution of the well, it would become at once highly injurious. It should 
also be borne in mind that an impure water might be drunk for years by people who have been accustomed to it, but strangers coming into the neighbourhood might suffer immediately.

Mr. Hehner urged the alteration of the word "injurious" to "dangerous," and moved a resolution to the effect that the change should be attempted to be made.

Dr. Hulse asked Dr. Hill what was the attitude taken by the chemists who were on the side of the defence.

Mr. CASSAL was of opinion that the phrase "injurious to health" was sufficiently elastic for the analyst to swear that such a water as that under discussion answered to that description. Mr. Fox has said that no person habitually drinking diluted sewage is ever a picture of health. The question as to the "injurious" character of the water was eminently one for a medical man. What would he say under the circumstances? $\mathrm{He}$ also asked Dr. Hill whether or no the water sediment was examined microscopically.

Dr. Hill, in reply to Mr. Lloyd and Dr. Dupré, said that he also knew of a case in which a stranger had suffered from drinking water innocuous to the inhabitants of a certain locality. He could not agree with Mr. Cassal as to the elasticity of the phrase "injurious to health," and thought that the position of a witness adopting that view would be untenable when exposed to cross-examination. $\mathrm{He}$ had not examined the deposit from the water, because it was only slightly turbid. With regard to what the President had said about the lead in Sheffield water, he did not think the cases were parallel. Lead is a tangible, easily detectable poison, but that present in impure water is not. He agreed that the nitrates shiould not be ignored; one could judge of a water, as of a man, by the company it kept. In respect of the question why he had not obtained legal advice, he had suggested the desirability of having a solicitor or barrister to conduct the case to the Inspector of Nuisances, who, however, thought it unnecessary. The case was decided summarily, and the chance of appeal lost from want of legal advice.

At the conclusion of the discussion on Dr. Hill's paper, Mr. Otto Hehner proposed, Dr. Bostock Hill seconded, and it was unanimously resolved,

"That a deputation from the Society of Medical Officers of Health and the Society of Public Analysts wait upon the President of the Local Government Board, and urge upon him the necessity of altering the wording of the 70th section, 'injurious to health' to 'dangerous to health.'" 